\title{
'|||||||||||||||||||||||||||||||||||||||||||||||||||||||||||||||||||.
}

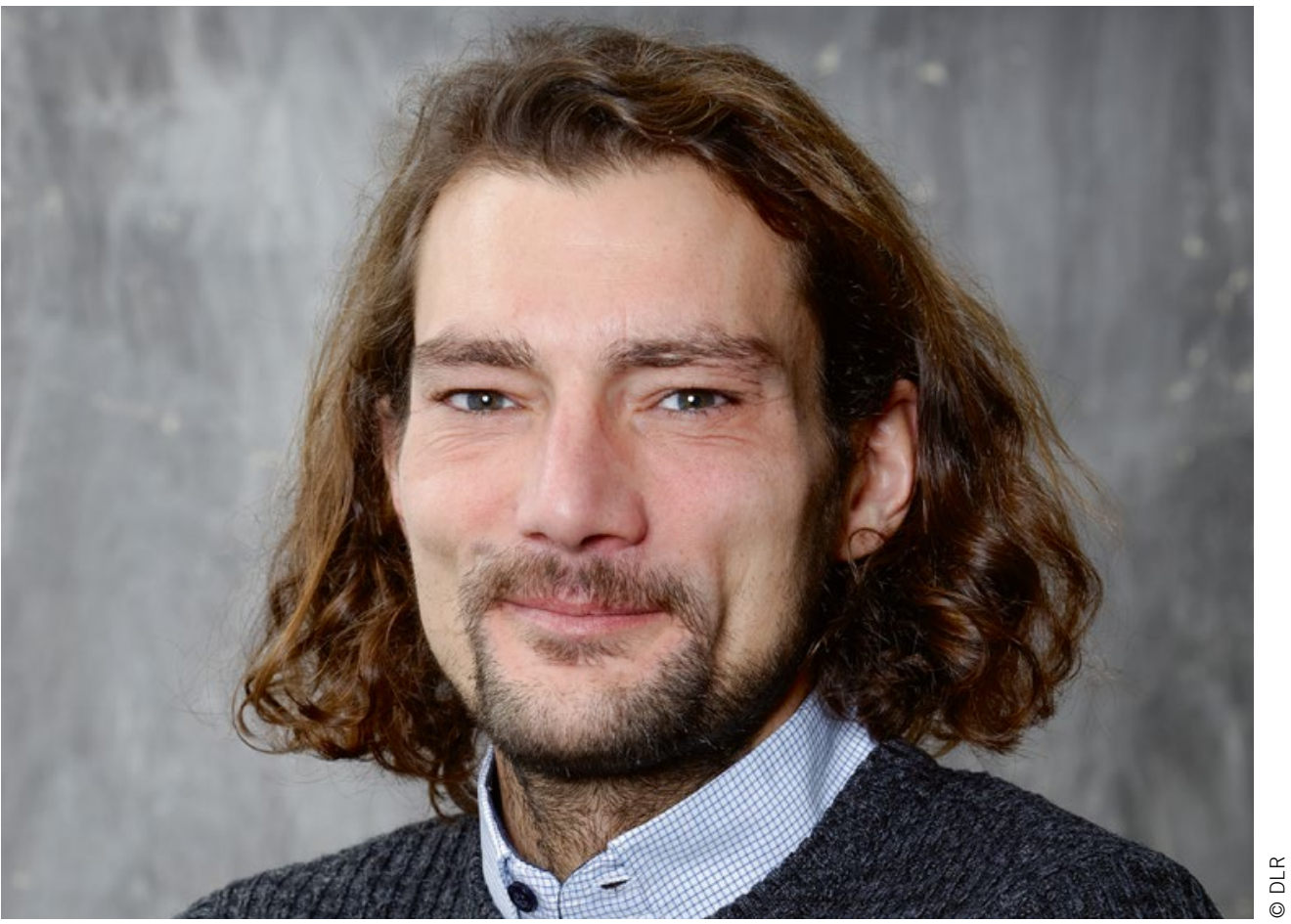

Dr.-Ing. Stephan Müller Wissenschaftlicher Mitarbeiter des Instituts für Verkehrsforschung beim Deutschen Zentrum für Luft- und Raumfahrt (DLR)

\section{Fahrerlose Lkw in zehn Jahren - Das braucht die Logistikbranche}

Hinsichtlich des automatisierten und vernetzten Fahrens im Lkw-Markt konzentrierten sich die Fahrzeughersteller in der Vergangenheit auf die Entwicklung von Lkw für zwei Einsatzbereiche: erstens auf das Konvoi-Fahren (Platooning oder elektronische Deichsel), bei dem in deutlich verringertem Abstand sicher hintereinander her gefahren werden kann, sowie zweitens auf das mobile Büro, in dem der Fahrer andere Tätigkeiten wie Termindisposition oder Kundengespräche durchführen kann, während das Fahrzeug die Fahraufgabe übernimmt.

Unsere Forschung am DLR im Projekt ATLaS zeigt aber, dass diese Ausrichtung der Technologieentwicklung für die Kunden in der Logistikbranche weniger relevant ist. Die Gründe hierfür sind vielfältig und reichen von „Wir können keine teure Technologie einkaufen, damit es der Fahrer auf Arbeit bequemer hat" bis zu „Unsere Kunden brauchen die bestellte Menge termingerecht und nicht drei Lkw-Ladungen, die im Konvoi gebündelt vor die Rampe fahren“.

Dennoch stößt die Möglichkeit des automatisierten und vernetzten Fahrens grundsätzlich auf ein enormes Interesse in der Logistikbranche. Die Technologie könne - so die Hoffnung vor allem eine Antwort auf zwei zentrale Herausforderungen der Branche bieten: den wachsenden Fahrermangel sowie den steigenden Kostendruck bei gleichzeitiger Margenreduktion. Daraus ergibt sich auf der Nachfrageseite eine recht konkrete Technologieanforderung: Laut unseren Forschungsergebnissen braucht es fahrerlose Sattelzüge. Und diese müssten in zehn Jahren verfügbar sowie zuverlässig einsetzbar sein. Denn in diesem Zeitraum muss eine Lösung für die genannten Herausforderungen entwickelt werden. Der Einsatzbereich von fahrerlosen Lkw liegt dabei vorrangig im Systemverkehr, zum Beispiel dem Nachtsprung. „Je standardisierter der Logistikprozess, desto wahrscheinlicher ist der Einsatz fahrerloser Lkw“, brachte es ein Top-Manager eines der von uns befragten Logistikunternehmen auf den Punkt.

Die gute Nachricht für die Fahrzeughersteller ist also: Mit der passenden Technologie können sie ein enormes Marktpotenzial erschließen. Um dies zu erreichen, ist aber von der derzeitigen Einführungsstrategie der Technologie in den Lkw-Markt abzusehen. Das heißt, kleine Schritte ab SAE-Level 2+ helfen nicht weiter. Vielmehr liegt die notwendige Strategie hier im direkten Technologiesprung zum fahrerlosen Lkw. Ob der damit verbundene hohe Kapitaleinsatz in Forschung und Entwicklung im relativ kurzen Zeitfenster von zehn Jahren machbar und erfolgsversprechend ist, müssen die OEMs also zeitnah abwägen. 